\title{
ÉTICA, CEGUEIRA MORAL E MODERNIDADE LÍQUIDA: DISCUSSÕES A PARTIR DE JOSÉ SARAMAGO E ZYGMUNT BAUMAN
}

\author{
[Ethics, Moral Blindness and Liquid Modernity: Discussions on José \\ Saramago and Zygmunt Bauman]
}

\author{
Mariana Costa do Nascimento ${ }^{1}$ \\ Terezinha Oliveira ${ }^{2}$
}

\begin{abstract}
Resumo: A modernidade líquida nos trouxe inúmeras repercussões, principalmente para as relações humanas. O turbilhoes de informações, advindos da globalização negativa, tornam as pessoas cada vez menos empáticas diante de situações catastróficas, como a queda de avião, rompimento de barragens, pandemias, furacões e etc. O novo individualismo atrelado ao enfraquecimento dos vínculos humanos e a dissolução da solidariedade repercutem em uma espécie de cegueira moral e ética dos indivíduos. O objetivo deste artigo é relacionar os excetos da obra Ensaio sobre a Cegueira de José Saramago (2017) com o conceito cegueira moral de Bauman. O livro narra a história de uma epidemia de cegueira branca que se espalha pela cidade causando situações caóticas. A cegueira vivenciada pelos personagens da literatura, não é decorrente de problemas físicos, mas está relacionada a perda de sensibilidade ao sofrimento dos outros, ou seja, trata-se de uma cegueira moral.
\end{abstract}

Palavras-chave: Educação; Ética; Cegueira moral; Saramago; Bauman.

\begin{abstract}
Liquid modernity has brought us countless repercussions, especially for human relations. The turmoil of information, due to negative globalization, makes people less and less empathic in the face of catastrophic situations, such as airplane crashes, dam breakages, pandemics, hurricanes and etc..The new individualism linked to the weakening of human bonds and the dissolution of compassion have repercussions on a kind of moral and ethical blindness of individuals. The aim of this article is to relate the passages of José Saramago's Blindness (2017) with Bauman's concept of moral blindness. The novel narrates the story of an epidemic of white blindness that spares throughout the city causing chaos. The blindness experienced by characters in the book is not due to physical problems, but related to the loss of empathy to the suffering of others, that is to say, moral blindness.
\end{abstract}

Keywords: Education; Ethics; Moral blindness; Saramago; Bauman.

\footnotetext{
1 Doutora em Educação. Docente temporária do Departamento de Fundamentos da Educação (DFE) - Universidade Estadual de Maringá (UEM). E-mail: marianacostadonascimento@gmail.com

2 Doutora em Educação. Docente do Departamento de Fundamentos da Educação (DFE) e do Programa de Pós-Graduação em Educação - Universidade Estadual de Maringá (UEM). E-mail: teleoliv@gmail.com
} 


\section{INTRODUÇÃO}

O processo de globalização nos proporcionou a quebra de fronteiras, principalmente em relação a circulação de mercadorias e de informações. Os meios de comunicação atuais nos permitem acompanhar em tempo real diversos tipos de notícias, como como queda de aviões, ataques terroristas, surtos epidêmicos, desenvolvimento de vacinas e medicamentos, descoberta de fosseis de animais em extinção, situação política e econômica de outros países e entre outros. São informações que viajam milhões de quilômetros em poucos segundos.

De acordo com Bauman (2007, p. 12), em um planeta aberto à livre circulação de informações e de mercadorias, o que acontece "em um determinado tem peso sobre a forma como as pessoas de todos os lugares vivem, esperam ou supõem viver". A quebra de fronteiras possibilitou que todas as sociedades se tornassem verdadeiramente abertas, seja materialmente ou intelectualmente, repercutindo ainda em um destino irreversível aos efeitos imprevistos da globalização negativa.

A falta de segurança é um dos resultados desse tipo de globalização, uma vez que em um planeta negativamente globalizado, a segurança não pode ser obtida e nem assegurada (BAUMAN, 2007). Nesse contexto de insegurança, o medo ganha a capacidade de se autoperpetuar e autofortalecer, saturando diariamente a existência humana. Nas palavras do autor, "o medo é reconhecidamente o mais sinistro dos demônios que se aninham nas sociedades abertas de nossa época. Mas é a insegurança do presente e a incerteza do futuro que produzem e alimentam o medo mais apavorante e menos tolerável" (BAUMAN, 2007, p. 32).

Colaborando a essas discussões, Safatle (2015) afirma que o medo não pode ser relacionado apenas a contemporaneidade, pois a construção das cidades no período medieval representou um dos principais incentivos para a proteção do perigo. De acordo com o autor, o medo constitui-se um afeto político central desde a idade média. Nesse período, o senhor feudal representava o Estado, legitimando poder e proteção aos servos. Na modernidade, essa instituição foi fundamental para a perpetuação do medo, uma vez que o Estado exerce paradoxalmente as funções de bombeiro e piromaníaco da vida social. Ele é bombeiro, pois fornece aos indivíduos o regramento social e a possibilidade de garantia de sua segurança. Por outro lado, é também o piromaníaco, porque lembra a todos e a todo momento os riscos e perigos que ocorrem e, consequentemente potencializa o medo de todos nós. Justifica, assim, sua existência para que a segurança dos indivíduos se mantenha.

Além das discussões sobre medo e segurança, Bauman (2007) afirma que o novo individualismo, o enfraquecimento dos vínculos humanos e a dissolução da solidariedade também estão impressos nos contornos sombrios da "globalização negativa". Para o autor, a busca por interesses próprios, aliada a insensibilidade são algumas das atitudes contribuem para a iniciação e manutenção da cegueira moral e ética na modernidade líquida. Ao discutir sobre esse conceito em sua obra, Bauman (2014, p. 16) afirma que o mal não se revela apenas em guerras ou em regimes totalitários, "mas com frequência quando deixamos de reagir ao sofrimento de outra pessoa, quando nos recusamos a compreender os outros, quando somos insensíveis e evitamos o olhar ético silencioso". 
A insensibilidade moral inclui, segundo o autor, o nosso esquecimento do outro, a recusa proposital em reconhece-lo. Trata-se, portanto, de um funcionamento típico de uma sociedade blasé, despreocupada e insensível a diferença (BAUMAN, 2007). Mas, como afirma o autor, o pecado da negligência moral pode se tornar objeto de arrependimento ou absolvição por meio de presentes, estes que auxiliam a aplacar a dor moral dos sujeitos. "A cultura consumista tem transformado as lojas e agências de serviços em uma farmácia de tranquilizantes. (BAUMAN, 2014).

Consideramos que a cegueira moral também está associada a falta de princípios éticos, isso porque os conceitos moral e ética são indissociáveis. De acordo com Romano (2002, p. 98) a ética apresenta origem grega (ethiké, ethikós) e refere-se a um conjunto de costumes e hábitos "introduzidos e reiterados num determinado tempo e sociedade, tornando-se quase automáticos nas consciências humanas, como se fossem uma segunda natureza”.

Aristóteles foi um dos primeiros filósofos a discutir sobre esse conceito nas obras Ética e Nicômaco (1991) Ética a Eudemo (2002) e Política (2019). Para Aristóteles, ética e política estabelecem relações dependentes. A política deve assegurar a todos o bem comum e para isso deve subordinar-se a ética, a fim de contemplar a felicidade de todos ou do maior número possível. A ética aristotélica, portanto, está relacionada a felicidade, pois o homem só é feliz quando realiza pelo e para qual foi feito, ou seja, quando ele é bom e virtuoso (NODARI, 1997).

Próximo a concepção aristotélica de ética, São Tomás de Aquino explicita a relação de responsabilidade do indivíduo com a sociedade na obra Suma de Teologia (2004). De acordo com Aquino, o bem ou mal praticado a um indivíduo afeta toda a sociedade. Nesse sentido, "o ato humano ainda que parecesse incidir apenas sobre a pessoa que agia, incidia sobre o conjunto dos homens" (CAVALCANTE; OLIVEIRA, 2012, p. 244). É por isso que todas as ações tinham a razão de mérito ou demérito, pois estavam de acordo com o entendimento da justiça (CAVALCANTE; OLIVEIRA, 2012).

Diante das considerações esboçadas sobre o conceito cegueira moral de Bauman (2007; 2014) e ética, procuramos neste artigo relacioná-los com excetos da obra Ensaio sobre a Cegueira de José Saramago (2017), já que a dissolução dos vínculos humanos, de princípios éticos e de solidariedade, permeia a literatura. O livro narra a história de uma epidemia de cegueira branca que se espalha pela cidade causando situações caóticas. A cegueira vivenciada pelos personagens da literatura, não é decorrente de problemas físicos, mas está relacionada a perda de sensibilidade ao sofrimento dos outros, ou seja, trata-se de uma cegueira moral.

Em relação aos autores utilizados em nosso artigo, cabe mencionar que Zygmunt Bauman (1925-2017) é sociólogo polonês e foi professor emérito das Universidades de Leeds e Varsóvia. Em sua produção intelectual, Bauman discute sobre o período contemporâneo, nomeado pelo autor como modernidade líquida e as repercussões para os relacionamentos humanos, educação, globalização, circulação de informações e mercadorias e etc. Modernidade líquida (2001), Tempos líquidos (2007), Capitalismo Parasitário (2010), Sobre Educação e Juventude (2013), Cegueira Moral (2014) são alguns dos títulos que se destacam em sua produção.

Por sua vez, José Saramago (1922-2010) foi escritor português. Recebeu o Prêmio Nobel de literatura em 1998. Entre seus escritos estão romances, ensaios e contos, sendo que as 
obras que se destacam, são: Evangelho Segundo Jesus Cristo (1991), O conto da ilha perdida (1997), Ensaio sobre a Cegueira (2017) e Ensaio sobre a lucidez (2004).

\section{ENSAIO SOBRE A CEGUEIRA: CONSIDERAÇÕES GERAIS}

Por que foi que cegámos. Não sei, talvez um dia se chegue a conhecer a razão, Queres que te diga o que penso, Diz, Penso que não cegámos, penso que estamos cegos, Cegos que veem, Cegos que, vendo, não veem (SARAMAGO, 2017, p. 310).

O enredo se passa em uma cidade não nomeada pelo o autor. A história inicia-se com um homem que aguarda o semáforo abrir. O sinal verde acende e "bruscamente os carros arrancaram, mas logo se notou que não tinha arrancado todos por igual" (SARAMAGO, 2017, p. 11). O primeiro da fila encontrava-se parado, enquanto os automóveis atrás dele buzinam e batem nos vidros fechados.

O carro parado não estava com problemas mecânicos, mas seu condutor estava imobilizado devido ao desespero de ter ficado cego repentinamente. "Estou cego, estou cego, repetia [...] enquanto o ajudavam a sair do carro, e as lágrimas, rompendo, tornaram mais brilhante os olhos que ele dizia estarem mortos" (SARAMAGO, 2017, p. 12). Esse personagem é nomeado como primeiro cego, pelo narrador, sua cegueira, assim como os demais da obra, assemelha-se a um nevoeiro, um mar de leite.

Para chegar em sua casa, o primeiro cego é ajudado por um homem (este que acaba roubando o seu carro). Em sua residência, a mulher do primeiro cego se surpreende com a cegueira repentina do marido e ambos decidem procurar um oftalmologista. Na consulta, o médico ao fazer o diagnóstico "não encontrou nada na córnea, nada na esclerótica, nada na íris, nada na retina, nada no cristalino, nada na mácula lútea, nada no nervo óptico, nada em parte alguma (SARAMAGO, 2017, p. 23).

O ladrão de carro, a mulher do primeiro cego e o médico são os próximos personagens a também cegarem. Os pacientes (rapariga dos olhos escuros e o menino estrábico) que o oftalmologista atendera depois do primeiro cego, também seriam acometidos pela cegueira. A cegueira desses personagens passaram para os demais da obra, para o farmacêutico e a camareira de hotel que a rapariga de olhos escuros teve contato, para o motorista que levou o primeiro cego e a mulher ao consultório do médico e para os policias que ajudaram o ladrão de carros chegar a sua casa, após cegar. A única personagem que não cegará, durante todo o enredo, é a mulher do médico.

Diante dos vários casos de cegueira na cidade, o governo decide isolar os cegos e os suspeitos em um manicômio desativado. Os cegos são divididos por camaratas. Os primeiros a serem transportados foram o médico e a mulher. Haviam soldados de guarda na ala externa. A parte interna era dividida por camaratas, sendo que cada uma continha duas filas de camas. "Havia mais camaratas, corredores longos e estreitos, gabinetes que deviam ter sido de médicos [...] uma cozinha que ainda não perdera o cheiro de má comida, um grande refeitório com mesas de tampos forrados de zinco, três celas acolchoadas até à altura de dois metros" (SARAMAGO, 2017, p. 47). Atrás do edifício, "havia uma cerca abandona- 
$\mathrm{da}$, com árvores mal cuidadas, os troncos davam a ideia de terem sido esfolados. Por toda a parte se via lixo" (SARAMAGO, 2017, p. 47).

Havia instruções, elaborados pelo governo, que eram transmitidas todos os dias aos isolados. No total, eram 15 regras: 1) As luzes deveriam ser mantidas acessas; 2) O abandono do edifício, sem autorização, significaria morte imediata; 3) Em cada camarata havia um telefone para contactar o exterior, a fim de solicitarem produtos de higiene e de limpeza; 4) Os internatos deveriam lavar manualmente as suas roupas; 5) Era sugerido a eleição de responsáveis por camarata; 6) Três vezes ao dia, eram depositadas caixas de comida na porta de entrada; 7) Os restos de comida deveriam ser queimados; 8) A queima seria realizada nos pátios interiores do prédio ou da cerca; 9) Os internatos deveriam ser responsáveis por todas as consequências negativas dessas queimas"; 10) Os bombeiros não interviriam em caso de incêndio; 11) Os internos não receberiam nenhum tipo de intervenção externa; 12) Em caso de morte, o cadáver deveriam ser enterrados, sem formalidades; 13) A comunicação da ala dos pacientes com a ala dos suspeitos se dava por meio do setor central do edifício; 14) Os suspeitos de contágio que vierem a cegar deveriam passar para a ala dos que já estão cegos; 15) As instruções eram transmitidas todos os dias para conhecimento dos novos internos (SARAMAGO, 2017).

Com o passar dos dias, chegam mais internos para o manicômio, começa a faltar comida e a relações de convivência são agravadas. O novo grupo de cegos, nomeado pelo narrador como cegos malvados/ladrões e localizados na ala esquerda (antes reservada aos contaminados), passam a exigir pagamento pela comida da ala direita. Inicialmente, o pagamento é feito por meio de objetos trazidos ao manicômio. Posteriormente, devido à falta de recursos dos cegos da ala direita, os cegos malvados/ladrões exigem que as mulheres sejam utilizadas como pagamento. Essa passagem de violência sexual pendura duas noites e encerra-se quando a mulher do médico ataca o chefe dos cegos malvados.

$A$ atitude da personagem demonstrou que a ala esquerda não aceitaria mais pagar pela comida (seja por meio de objetos ou com as mulheres). Nesse momento, as relações entre os internos tornam-se ainda mais acirradas. Durante o conflito, uma das personagens coloca fogo nas camas das camaratas dos cegos malvados e o manicômio pega fogo. Ao tentarem escapar das chamar, os personagens percebem que não havia mais soldados do lado de fora e que o portão se encontrava aberto, estavam livres. Alguns cegos conseguirem escapar, mas outros faleceram queimados ou esmagados pelos outros cegos.

O grupo dos primeiros cegos é um dos personagens que conseguem escapar. Ao saírem percebem a situação caótica que se encontra a cidade, todos os cidadãos também haviam cegados e encontravam-se abrigados em casas, lojas, farmácia, lavanderias, supermercados da cidade. Os lixos estavam espalhados, o mau cheiro se desprendia das lixeiras, haviam animais e pessoas mortas nas ruas.

Fora do manicômio, a mulher do médico continua ajudando o grupo de primeiros cegos, a encontrar um lugar seguro, alimento e a tentar encontrar o paradeiro de amigos e familiares, não vistos desde o início da epidemia de cegueira. A obra encerra-se quando os cegos recuperam a visão. O homem do semáforo é o primeiro a ser curado, em seguida a rapariga dos olhos escuros, posteriormente o médico e os demais personagens. 


\section{ANÁLISE E DISCUSSÃO DA OBRA}

Eu acho que vamos morrer todos, é uma questão de tempo, Morrer sempre foi uma questão de tempo, disse o médico, Mas morrer só porque se está cego, não deve haver pior maneira de morrer, Morremos de doenças, de acidentes, de acasos, E agora morremos também porque estamos cegos, quero dizer, morremos de cegueira e de cancro, de cegueira e de tuberculose, de cegueira e de sida, de cegueira e de enfarte, as doenças poderão ser diferentes de pessoa para pessoa, mas o que verdadeiramente agora nos estás a matar é a cegueira (SARAMAGO, 2017, p. 282).

O Ensaio sobre a cegueira nos faz refletir sobre a dissolução dos vínculos humanos e de princípios éticos, além da perda de sensibilidade ao sofrimento alheio. A obra retrata como o ser humano, em situações caóticas, busca a atender a interesses próprios não considerando, portanto, que as ações praticadas a um indivíduo afetam todos de uma sociedade.

Nessa seção trazemos excertos da obra de Saramago e os relacionamos com os conceitos cegueira moral de Bauman e ética de Aristóteles. Com isso, não pretendemos utilizar a literatura como simples ilustração dos conceitos dos autores, já que entendemos estes são complexos e impossíveis de serem reduzidos a alguns exemplos. O que pretendemos é promover discussões relacionando os três autores, Saramago, Bauman e Aristóteles.

Logo no início da obra, observamos que o ladrão se aproveita da cegueira do homem do semáforo para furtar o seu carro. A atitude que, a princípio, foi interpretada pelo primeiro cego como sinal de solidariedade, foi utilizada como oportunidade para ocorrência de um crime. O diálogo entre o primeiro cego e sua mulher sobre o fato evidenciam a cegueira ética e moral do ladrão de carros.

O santinho do teu protector, a boa alma, levou-nos o carro. Não pode ser, não deve ter visto bem, Claro que vi bem, eu vejo bem, as últimas palavras saíram-lhe sem querer, Tinhas-me dito que o carro estava na rua do lado, emendou, e não está, ou então deixaram-no noutra rua, Não, não, foi nessa, tenho certeza, Pois então levou sumiço, Nesse caso, as chaves, Aproveitou-se da tua desorientação, da aflição em que estavas, e roubou-nos, E eu que nem o quis deixar entrar em casam, por medo, se tivesse ficado a fazer-me companhia até tu chegastes [...] Pode ser que apareça, Ah, pois, amanhã bate-nos ai à porta a dizer que foi uma distracção, a pedir desculpa, e a saber se estás melhorzinho (SARAMAGO, 2017, p. 20, grifo nosso).

Em outra passagem da obra, verificamos condutas divergentes do conceito cegueira moral de Bauman e, portanto, convergentes com o conceito ética de Aristóteles e Aquino. Podemos inferir que quando o médico entra em contato com o governo para alertar sobre a epidemia de cegueira e a necessidade de isolamento, estamos diante de um ato de solidariedade para o restante da comunidade. Isso porque, isolar os cegos e os suspeitos significaria proteger os demais da cegueira. A conversa entre o médico e sua mulher evidencia que oftalmologista prioriza o bem comum da sociedade. 
E agora, o que vamos fazer, pergunta entre lágrimas, Avisar as autoridades sanitárias, o ministério, é o mais urgente, se se trata realmente de uma epidemia é preciso tomar providências, Mas uma epidemia de cegueira foi coisa que nunca se viu, alegou a mulher, querendo agarrar-se a essa derradeira esperança, Também nunca se viu um cego sem motivos aparentes para o ser, e neste momento já há pelo menos dois (SARAMAGO, 2017, p. 39, grifo nosso).

A empatia e a primazia pelo bem-estar coletivo são recorrentes nas atitudes da mulher do médico. Em várias passagens evidenciamos esse tipo de conduta, desde a sua entrada no manicômio. No excerto retirado da obra relatado a seguir, a mulher do médico comenta com seu marido que deseja contar aos outros que ela enxerga, pois desta forma poderia dividir de forma adequada a comida entre os internos.

[...] não aguento, não posso continuar a fingir que não vejo, Pensa nas consequências, o mais certo é que depois tentem de fazer de ti uma escrava, um pau mandado, terás de atender a todos e a tudo, exigir-te-ão que os alimente, que os laves, que os deites e os levantes, que os leves daqui para ali, que os assoes e lhes seques as lágrimas, gritarão por ti quando estiveres a dormir, insultar-te-ão se tardares, $\mathrm{E}$ tu, como queres que ti que continue a olhar para estas misérias, tê-las permanentemente diante dos olhos, e não mexer um dedo para ajudar, O que fazer já é muito, Que eu faço, se a maior preocupação é evitar que alguém se aperceba que eu vejo, Alguns irão odiar-te por veres, não creias que a cegueira nos tornou melhores, Também não nos tornou piores, Vamos a caminho disso, vê tu só o que se passa quando chega a altura de distribuir a comida, Precisamente, uma pessoa que visse poderia tomar a seu cargo a divisão dos alimentos por todos os que estão por aqui, fazê-lo com equidade, com critério, deixaria de haver protestos acabariam essas disputas que me põem louca, tu não sabes o que é ver dois cegos a lutarem, Lutar foi sempre, mais ou menos, uma forma de cegueira (SARAMAGO, 2017, p. 135, grifo nosso).

Por outro lado, com os outros personagens da obra, evidenciamos a busca por interesses próprios e a consequente falta de solidariedade com os demais (cegueira moral e ética). Evidenciamos esse tipo de conduta quando os cegos malvados/ladrões exigem pagamento dos cegos da ala direita para receber a comida.

[...] a partir de hoje seremos nós a governar a comida, ficam todos avisados, e que ninguém tenha a ideia de ir lá fora busca-la, vamos pôr guardas nesta entrada, sofrerão as consequências de qualquer tentativa de ir contra as ordens, a comida passa a ser vendida, quem quiser comer, paga. Pagamos, como, perguntou a mulher do médico [...] Cada camarata nomeará dois responsáveis, esses dicam encarregados de recolher os valores, todos os valores, seja qual for a sua natureza, dinheiro, joias, anéis, pulseiras, brincos, relógios, o que lá tiveram, e levam tudo para a terceira camarata do lado esquerdo, que é onde nós estamos, e se que- 
rem um conselho de amigo, que não lhes passe pela cabeça tentarem enganar-nos (SARAMAGO, 2017, p. 140, grifo nosso).

Com o passar dos dias, os objetos utilizados como pagamento se acabaram e as mulheres da ala direita foram exigidas como forma de pagamento. Como já estavam a alguns dias sem comer, os cegos acabam aceitando a proposta. A mulher do médico é a primeira a se manifestar, sacrificando-se pelas demais mulheres do grupo.

Passada uma semana, os cegos malvados mandaram recado de que queriam as mulheres. Assim, simplesmente, Tragam-nos as mulheres. Esta inesperada, ainda que não de todo insólita, exigência causou a indignação que é fácil imaginar, os aturdidos emissários que vieram com a ordem voltaram logo para comunicar as camaratas, as três da direita e as duas da esquerda, sem excepção dos cegos e das cegas que dormiam no chão, haviam decidido por unanimidade, não acatar a degradante imposição, objetando que não podia rebaixar a esse ponto a dignidade humana, neste caso feminina, e que se na terceira camarata lado esquerda não havia mulheres, a responsabilidade, se a havia, não lhes poderia ser assacada. A resposta foi curta e seca, Se não nos trouxerem, não comem (SARAMAGO, 2017, p. 165, grifo nosso).

Eu vou, disse, não sabia que estas palavras eram o eco das que na primeira camarata lado direito haviam sido ditas pela mulher do médico, Eu vou, nesta camarata daqui as mulheres são poucas, talvez por isso os protestos não foram tão números nem tão veementes, estava a rapariga dos olhos escuros, estava a mulher do primeiro cego, estava a empregada do consultório, estava a criada do hotel, estava uma que não se sabe quem seja, estava a que não podia dormir, mas esta era tão infeliz, tão desgraçada, que o melhor seria deixa-la em paz, da solidariedade das mulheres que não tinham por que beneficiar só os homens (SARAMAGO, 2017, p. 167, grifo nosso).

Ao saírem do manicômio, os personagens se abrigam em uma lavanderia. A mulher do médico sai a procura de alimentos para o grupo dos primeiros cegos. No armazém, a mulher pensa que não deveria levar todos os produtos, mas acaba enchendo suas sacolas. Inferimos que a atitude da mulher do médico aproxima-se das discussões sobre ética, pois ao levar vários alimentos, a mulher estaria deixando outras pessoas sem comida. Nesse sentido, como afirma Aquino (2004), o bem ou mal praticado a um indivíduo afeta toda a sociedade.

Encheu um dos sacos, Será que tudo de comer, perguntava-se inquieta. Passou a outras prateleiras, e na segunda delas o inesperado aconteceu, a mão cega, que não podia ver aonde ia, tocou e fez cair umas pequenas caixas. O ruído que fizeram, ao chocarem contra o solo, quase fez parar o coração da mulher do médico, São fósforos pensou [...] a luz existe e eu tenho olhos para ver, louvada seja a luz. 
A partir de agora a colheita seria fácil. Começou pelas caixas de fósforos, e foi um saco quase cheio, Não é preciso leva-las todas, dizia-lhe a voz do bom senso, mas ela não deu atenção ao bom senso, depois as trémulas chamas dos fósforos foram mostrando as prateleiras, para cá, para lá, em pouco tempo os sacos firam cheios, o primeiro teve de ser despejado porque não continha nada que prestasse [...] E quando a comida se acabar poderei voltar por mais pensou (SARAMAGO, 2017, p. 224, grifo nosso).

\section{CONSIDERAÇÕES FINAIS}

A análise da obra O Ensaio sobre a Cegueira nos permitiu discutir sobre a cegueira moral e ética, a partir de Bauman (2007; 2014), Aristóteles (1991; 2022; 2019) e Aquino (2004). A cegueira vivenciada pelos personagens da literatura, não é decorrente de problemas físicos, mas está relacionada à perda de sensibilidade e ao sofrimento alheio.

Os resultados encontrados indicam que a maior parte dos personagens da história apresentam características de cegueira ética e moral, uma vez que demonstram a busca por interesses próprios e falta de empatia com os demais. A mulher do médico é a única personagem que não é acometida pela cegueira. Em vários momentos da história, evidenciamos o pensamento no grupo e condutas de empatia da personagem, características que auxiliam na sobrevivência, principalmente dos primeiros cegos.

Para concluir, pontuamos uma analogia da obra com a instituição escolar. Em suas práticas em sala de aula, cabe ao docente demonstrar condutas éticas e morais com seus alunos/as, além de orientá-los sobre as repercussões desse tipo de cegueira que está relacionada a dissolução dos vínculos humanos e de princípios éticos. 


\section{REFERÊNCIAS}

ARISTÓTELES. Ética e Nicômaco. Tradução de Leonel Vallandro e Gerd Bornheim. São Paulo: Nova Cultura, 1991.

ARISTÓTELES. Ética a Eudemo. Tradução Edson Bini. São Paulo: Edipro, 2002.

ARISTÓTELES. Política. Tradução Maria Aparecida de Oliveira Silva. São Paulo: Edipro, 2019.

CAVAlCANTE, T.M.; OLIVEIRA, T. Intenção educacional da ética de Tomás de Aquino no contexto citadino no século XIII. Educação em Revista, Belo Horizonte, v.28, n.2, p.225-256, jun.2012.

BAUMAN, Z. Modernidade líquida. Rio de Janeiro: Zahar, 2001.

BAUMAN, Z. Tempos líquidos. Rio de Janeiro: Zahar, 2007.

BAUMAN, Z. Capitalismo parasitário. Rio de Janeiro: Zahar, 2010.

BAUMAN, Z. Sobre educação e juventude. Rio de Janeiro: Zahar, 2013.

BAUMAN, Z. Cegueira moral: a perda da sensibilidade na modernidade líquida. Rio de Janeiro: Zahar, 2014.

NODARI, P.C.A ética aristotélica. Síntese Nova Fase, Belo Horizonte, v.24, n. $1997,78$.

SAFATLE, V. O circuito dos afetos: corpos políticos, desamparo e fim do indivíduo. Belo Horizonte: Autêntica, 2016.

SARAMAGO, J. Evangelho Segundo Jesus Cristo. São Paulo: Companhia das Letras, 1991.

SARAMAGO, J. O conto da ilha perdida. São Paulo: Companhia das Letras, 1997.

SARAMAGO, J. Ensaio sobre a lucidez. São Paulo: Companhia das Letras, 2004.

SARAMAGO, J. Ensaio sobre a cegueira. São Paulo: Companhia das Letras, 2017.

ROMANO, R. Ética, Ciência e Universidade: entrevista com Roberto Romano. Interface Comunicação, Saúde e Educação, São Paulo, v.6, n.10, p. 97-110, fev.2002.

TOMÁS DE AQUINO. Suma Teológica. São Paulo: Edições Loyola, 2004. 